\section{DIGITAL COMMONS \\ @ UNIVERSITY OF SOUTH FLORIDA}

\section{ABO: Interactive Journal for Women in the Arts, 1640-1830}

\title{
\#MeToo or "Me Too"?: Defining Our Terms
}

Caitlin L. Kelly

Case Western Reserve University, caitlin.I.kelly18@gmail.com

Follow this and additional works at: https://digitalcommons.usf.edu/abo

Part of the Educational Methods Commons, English Language and Literature Commons, and the Feminist, Gender, and Sexuality Studies Commons

\section{Recommended Citation}

Kelly, Caitlin L. (2020) "\#MeToo or "Me Too"?: Defining Our Terms," ABO: Interactive Journal for Women in the Arts, 1640-1830: Vol.10: Iss.2, Article 4.

http://doi.org/10.5038/2157-7129.10.2.1222

Available at: https://digitalcommons.usf.edu/abo/vol10/iss2/4

This Pedagogy is brought to you for free and open access by Digital Commons @ University of South Florida. It has been accepted for inclusion in ABO: Interactive Journal for Women in the Arts, 1640-1830 by an authorized administrator of Digital Commons @ University of South Florida. For more information, please contact digitalcommons@usf.edu. 


\title{
\#MeToo or "Me Too"?: Defining Our Terms
}

\begin{abstract}
How we talk about misogyny and sexual violence in literary texts matters-to our students, to our colleagues, and to the future of the humanities and of higher education-and the "Me Too" movement has revived with new urgency debates about how to do that. In this essay, I explore the ethical implications of invoking the "Me Too" movement in the classroom, and I offer a model for designing a course that does not simply present women's narratives as objects of study but rather uses those narratives to give students opportunities and tools to participate in the "Me Too" movement themselves. To re-think eighteenth-century women's writing in light of "Me Too," I contend, is to participate in the movement, and so in our teaching we must engage with the ethics of the movement as well as the subject matter.
\end{abstract}

\section{Keywords}

\#MeToo, women's writing, pedagogy, eighteenth century

\section{Creative Commons License}

\section{(c) (1) (8)}

This work is licensed under a Creative Commons Attribution-Noncommercial 4.0 License 


\section{\#MeToo or "Me Too"?: Defining Our Terms}

\section{The movement and the classroom}

Tarana Burke founded the "Me Too" movement in 2006 after more than a decade working with young women of color in low wealth communities in Alabama and New York. Recalling an encounter with a young girl who attempted to share her experiences of sexual violence with her, Burke recounts how overwhelmed she found herself and how much pain she felt and caused in the way she responded. As Burke describes it, she was unable to "even bring [herself] to whisper...me too" in response to the teenager's confession (Me Too.). From that experience, the "Me Too" movement was born, with its goal to "to bring resources, support, and pathways to healing where none existed before" and to begin "building a community of advocates determined to interrupt sexual violence wherever it happens" (Me Too.).

In October 2017 "Me Too" was invoked again in a very different context by actress Alyssa Milano. In the wake of the revelations of film producer Harvey Weinstein's decades of sexual harassment and assault of women, Milano asked her followers on Twitter to reply "Me Too" if they had been sexually harassed or assaulted (@Alyssa_Milano). Within days, tens of thousands of women had replied. Milano herself was unware of Burke's organization, and undoubtedly so were many of women who replied to her tweet. However, Milano quickly acknowledged that her invocation of the phrase was coincidence when told about Burke and the two began to speak publicly together about their shared goals in using the phrase "Me Too" ("I was just made aware").

Even though Burke and Milano began to work together, the visibility afforded to Milano because of her celebrity status poses challenges for teachers who want to invoke the "Me Too" movement in the classroom setting. Though our students are most likely to be familiar with the movement through Milano's tweet and the subsequent media coverage of sexual harassment and assault cases in the months that followed it, neglecting Burke's role erases the work of women of color in the creation of the movement. So how might teachers push back against the tendency to reduce the "Me Too" movement to its hashtag activism element that does not speak to the experiences of the diverse women in our classrooms? This essay explores what it means to engage with the "Me Too" movement in the teaching of eighteenth-century women writers, and it invites teachers to consider the difference between "Me Too" and \#MeToo, and what invoking one over the other means in the classroom.

In this essay, I offer as a thought experiment and example a course I taught for the first time in the spring of 2019 that focused on novels by women published in the 1790s. Ultimately, I attempted to bring together Burke's "Me Too" movement and Milano's hashtag \#MeToo by focusing on where they intersect: the power of women's stories of survival. ${ }^{1}$ Burke's movement was born out of a need for language for sharing experiences and responding to survivors, and the number of responses Milano's tweet received in such a short period of time can be seen as a testament to that need that Burke had recognized in 2006. Over the course of the semester, students read Ann Radcliffe's A Sicilian Romance (1790), Susanna Rowson's Charlotte Temple (1791), and Mary Hays's The Victim of Prejudice (1799) alongside accounts such as Susan Fowler's blog post on her experiences working at Uber, Monica Lewinsky's Vanity Fair essay 
on her time working at the White House during the Clinton presidency, and Seo-Young Chu's creative nonfiction piece on her experiences in academia in Entropy. In other words, we approached both the novels and the contemporary accounts as narratives of survivors of sexual violence.

\section{"Me Too" and teaching eighteenth-century women writers}

For many scholars of literature of the long eighteenth century, acknowledging in the classroom the impact of sexual violence and misogyny in the literature we teach and study is nothing new: the idea of teaching Samuel Richardson's Pamela (1740) or Eliza Haywood's Fantomina (1725) without foregrounding issues of coercion and consent is unimaginable. Yet, as these discussions have resurfaced because of the "Me Too" movement, it is clear there is still much work to be done. For those who continue to fail to see sexual violence as central to much of the literature of the long eighteenth century, the "Me Too" movement revives the issue with a new sense of urgency. For those who already engage with these issues in the classroom, the "Me Too" movement provides a new access point for the conversations they are already having with their students.

In some sense, the "Me Too" movement holds the potential to accomplish what Catherine Ingrassia calls "reviving the strange" in eighteenth-century women's writing. Where decades of recovery work has given us so many texts and resources for teaching women's writing, Ingrassia cautions us to not get too comfortable with the progress we have made and "risk losing a heightened awareness of strange and wonderful interpretative possibilities" (13). Using Samuel Johnson's definitions of "strange" as a framework, Ingrassia offers examples of how we can create a sense of "estrangement" in the classroom (13), whether pushing back against assumptions about gender and genre or in using the vast primary text resources we have available to us. In the approach that I describe in this essay, I aim to demonstrate how the "Me Too" movement can create a productive distance between us and the women writers and women's writing that we study, evoking just this sense of estrangement.

To return to questions of recovery, the centrality of storytelling to the "Me Too" movement also makes it a natural extension of feminist criticism in the field, which recognizes the particular power that the act of writing holds for women. In 1989 in The Sign of Angellica Janet Todd cites Mary Wollstonecraft and Aphra Behn as examples of the way "that writing was an act of selfassertion for women" (4), also observing that "history like fiction works through narrative and selection" (8). Yet, as Paula R. Backscheider and John J. Richetti acknowledged around the same time, much of the critical attention paid to women's fiction "falls far short of evoking the special power and relevance (and pathos) of women's narratives" (xiv). Referencing the sexual violence that is present in so much early women's fiction, they point to fictional narratives "as one of the few places in which women could speak for themselves, could represent women's experiences, could express their needs, their nightmares, and their utopian hopes, and escape the masculine myth of the female" (Backscheider and Richetti xv). Invoking "Me Too" as an extension of the feminist work in literary criticism over the last three decades allows us to put this foundational work into practice once again, and that is especially important for the women in our classrooms. As Adrienne Rich argued in 1978 in "Taking Women Students Seriously," women need to know "her own history, her much politicized biology, an awareness of the creative work of women of 
the past" and that "Without such knowledge women live and have lived without context" (24). Forging connections between the eighteenth century and today through women's narratives of their lived experience is one way to provide that context.

\section{An approach}

In thinking about how to bring together women's narratives of past and present in my spring 2019 course, I focused on two core concepts derived from the "Me Too" movement. The first concept was that sharing stories of women's experiences of misogyny and sexual violence through written narratives, whether fiction or nonfiction, can play an important role in social change; the reading of both eighteenth-century novels and contemporary essays addressed this first concept. The second concept was the "Me Too" movement's emphasis on affecting change, whether through enabling individuals to process their experiences or by enacting large-scale social reforms; writing-based assignments that prompted students to think about how women's written accounts of misogyny and sexual violence affect both individuals and society attempted to address this second concept. This approach was largely successful: there was no resistance to the subject matter or why we were taking it up in the context of a general education seminar, and the students' work demonstrated thoughtful, sincere engagement with the course readings and the questions that reading raised. While I was not aware at the time of the work of Corrine C. Bertram and M. Sue Crowley on teaching about sexual violence, I now suspect that the course worked because it accomplished the two things that they recommend: it foregrounded intersectionality and systemic oppression as a context for understanding sexual violence and it validated as a part of the learning process the value of students' feelings about the course topic and our readings (68-69).

Because the course was a general education seminar that brought together mostly first-year students from across the disciplines, we first needed to acquire a common language. Framing the pairings of the eighteenth-century novels and contemporary narratives in my course was Kate Manne's landmark Down Girl: The Logic of Misogyny. Manne's study, the first dedicated to an academic examination of misogyny, brings philosophical approaches to bear on recent acts of violence against women. Manne's thesis locates misogyny not in the realm of the personal but rather the political: "misogyny ought to be understood as the system that operates within a patriarchal social order to police and enforce women's subordination and to uphold male dominance" (33). In framing sexual violence as political and systemic, students were able to point to the explicit violence in Radcliffe - women abducted, held captive, etc. - as a physical manifestation of the violence inflicted by the patriarchal system in denying women any sort of agency. In Charlotte Temple, even without knowing the tropes of the seduction narrative, students quickly honed in on the thin line between seduction and abduction, consent and coercion. Though Rowson never depicts or even alludes to sexual assault in the novel, the students were able to make sophisticated arguments that Charlotte had indeed been the victim of rape because of their understanding of affirmative consent and manipulation tactics like gaslighting. By the time we read The Victim of Prejudice, with its explicit depictions of physical violence and emotional abuse, the students were able to recognize how politically radical Hays was, and how she was breaking generic and societal conventions in the novel. 
In turn, Down Girl also enabled students to draw connections between A Sicilian Romance, Charlotte Temple, and The Victim of Prejudice and the contemporary narratives of women like Fowler, Lewinsky, and Chu. Through these narratives of past and present, we were able to think about the choices women might make in how they tell their stories, and how fiction and nonfiction can accomplish the same goals. What was it that Radcliffe gained from the conventions and tropes of the gothic novel? Why would Seo-Young Chu choose creative nonfiction as a mode for sharing her story while Susan Fowler chose a blog post? Why didn't Rowson explicitly write about rape as Hays or Monica Lewinsky did? What do we make of Rowson and Lewinsky both centering their narratives on consent rather than on the actual acts of assault? In the context of this class on "Me Too" and women's writing, the differences between the eighteenth-century and contemporary writers proved to be productive ones that these primarily first-year students with no background in late eighteenth-century literature and culture were equipped to encounter.

Where it would have been easy to reduce today's "Me Too" stories to the public shaming of individual powerful men and the fiction of the long eighteenth century to tales of bad men taking advantage of naïve women, this did not happen in the course. In part, this can be attributed to the familiarity of Manne's framing of misogyny and sexual violence to the students. For students who were in high school when the rapes of unconscious female students at Steubenville High School in 2012 and Stanford University in 2015 received national media attention, the language in Down Girl was familiar (and Manne discusses the Stanford case at length). Between those two cases, in 2014, the Obama Administration launched the "It's On Us" initiative to end sexual assault on campus, which included new federal guidance on reporting and responding to sexual assault (Somander). For many students in college today, the "It's On Us" campaign with its new federal guidance for schools, alongside the Steubenville and Stanford cases, radically changed the conversation about sexual violence. ${ }^{2}$ As a result, many of these students came to campus with a much more nuanced understanding of sexual violence, most notably the concept of affirmative consent, than their predecessors.

Having a shared language for talking about these narratives addressed the first core element guiding me, which was to help us to recognize how putting experience into words can be empowering for many women both today and in the eighteenth century. As Manne says of the word "misogyny," it is "increasingly being used to refer to a problem that women need a name for" (49). Manne's interest in language here resonates strongly with Burke's use of "Me Too": both emphasize women's need for language to talk about their experiences as "women in a man's world" (Manne 33). The second core concept I hoped to address through our class activities and assignments. Both Burke and Milano urge us to listen to and acknowledge women's experiences and then respond to them meaningfully, and assignments can be venues for students to do that. For example, I drew on reading journals as a space for students to engage with the "Me Too" movement in ways that they connected with personally, without forcing them to disclose or justify those motivations publicly. I also assigned an adaptation project that asked students to consider how a writer or character might share their experiences today, prompting them to think about the systemic factors at play in the eighteenth century and to compare those to our own time. I turned the reading schedule over to the students at the end of the semester in an effort to align the course with the movement's ethics and its call for us all to take responsibility and to 
take action. Similarly, the research project was designed so that students had the opportunity to apply what they were learning to cases, policies, and initiatives in their own communities.

Yet, assignments that provide opportunities for students to share their own experiences can have emotional, social, and legal consequences for both us and for our students. We know that women's voices are frequently silenced in the classroom, even as women make up the majority of undergraduate populations today (Bender-Slack 19-20) and that this has a devastating effect on class discussions because "how a text is understood is also determined by who is engaging in that discourse" (Bender-Slack 15). The narrative underpinnings of the "Me Too" movement though can provide students with a model of discourse that privileges women's voices and experiences, and that holds the potential to alter the course and impact of discussions of the texts we assign in our courses. However, it is imperative that teachers recognize that the work of a course like this can be traumatic, and students should know how to access support when they need it. As the Association of American Universities' 2019 Survey on Sexual Assault and Misconduct demonstrates, sexual violence happens to our students and on our campuses at alarming rates that are increasing rather than decreasing (“AAU Releases 2019 Survey”).

Addressing these challenges means both believing and believing in students as Catherine Denial urges us to do; she explains, "believing in students means seeing them as collaboratorsbelieving they have valuable contributions to make to the way in which syllabi, assignments, and assessments are designed, and life experiences that should be respected in the classroom" ("A Pedagogy of Kindness"). For example, students might need to approach projects differently than we expect when we ask them to engage with first-hand, and even fictional, accounts of sexual harassment and assault, and we need to be ready and willing to accommodate those situations. Some students might want to use their projects as a way to process their own experiences, and we must also be prepared for that. ${ }^{3}$ In turn, students need to be aware of the role of faculty as mandatory reporters, and instructors need to be prepared to respond to them and, potentially, guide and support them through the reporting process should they want to speak or write from personal experience. Faculty should also make information for services such as the counseling center, student health services, women's and LGBT centers, student advocates, etc. visible and easily accessible to students, such as in the syllabus and course website. However, visibility and accessibility is not enough; in a class that takes up narratives of sexual violence as objects of study, teachers must be careful that policies and resources do not inadvertently silence students' narratives. Consulting with their campus Title IX office can ensure that faculty understand their legal responsibilities, and their institution's women's and LGBT centers can help them to navigate those responsibilities in a way that does not silence survivors. Despite the labor involved in doing this, acknowledging that our classrooms are part of larger communities and that our students cannot leave their experiences in those communities at the door is an important, though small, way that we can support our students and help to change the culture on our campuses. Even so, this work may not be possible for the many instructors with precarious employment who are already overworked and undercompensated; for those in a position to do so, advocating for the institutional support and resources needed to do this work is also important.

In the end, my experience teaching a course that brought together eighteenth-century women's writing and contemporary "Me Too" narratives confirmed my suspicions that the "Me Too" 
movement could be a productive way to engage students with a time and literature that can often seem disconnected from their own experiences. The focus on narrative and agency, and the power of women's voices, that is shared by women writing about their experiences of misogyny, sexual harassment, and sexual assault across the centuries does indeed make the "Me Too" movement a powerful touchstone for our students. I saw that firsthand in the ways that my students, none with prior knowledge of eighteenth-century literary culture, drew on their understanding of affirmative consent and rape culture to raise sophisticated questions about the novels and to offer nuanced interpretations of them. The experience of teaching this course, however, also reinforced for me the need to be intentional in parsing out what we mean when we invoke those words "Me Too." In short, throughout the process of designing, teaching, and reflecting on this course, what I learned was that while it is productive to bring \#MeToo into the conversation, we must be committed to making space in the classroom to do the work of the movement and to allow the discussion to include "Me Too."

\footnotetext{
${ }^{1}$ In this essay, when I refer to the "Me Too" movement I do so using Burke's formulation of the phrase (as opposed to the hashtag) because it captures both the awareness-raising element of the movement as well as the communitybased work of supporting survivors.

${ }^{2}$ The Association of American Universities reported "significant increases from 2015 to 2019 in student reports of their knowledge about school definitions and procedures related to sexual assault and other sexual misconduct" ("AAU Releases 2019 Survey"). These findings could reflect the impact of the "It's On Us" initiative and federal guidance on responding to and preventing sexual violence on campus.

${ }^{3}$ Research pioneered by James W. Pennebaker has shown that writing can be a productive part of a therapeutic approach to dealing with trauma; for an overview, see "Writing about Emotional Experiences as a Therapeutic Process." It should be noted, however, that writing about an experience of harassment or assault would be considered disclosure and that faculty members, unlike therapists, are required to report that disclosure.
}

\section{Works Cited}

“AAU Releases 2019 Survey on Sexual Assault and Misconduct." Association of American Universities. 15 October 2019. https://www.aau.edu/newsroom/press-releases/aaureleases-2019-survey-sexual-assault-and-misconduct. Accessed 20 June 2020.

@,Alyssa_Milano. "If you've been sexually harassed or assaulted write 'me too' as a reply to this tweet." Twitter, 15 October 2017, 1:21pm, https://twitter.com/Alyssa_Milano/status/919659438700670976. Accessed 20 June 2020.

---. "I was just made aware of an earlier \#MeToo movement, and the origin story is equal parts heartbreaking and inspiring." Twitter, 16 October 2017, 4:24pm, https://twitter.com/alyssa_milano/status/920067975016624128?lang=en . Accessed 20 June 2020. 
Backscheider, Paula R. and John J. Richetti. "Introduction.” Popular Fiction by Women 16601730. Oxford UP, 1996. ix-xxiii.

Bender-Slack, Delane. "The Role of Gender in Making Meaning of Texts: Bodies, Discourses, and Ways of Reading." Feminist Teacher 20.1 (2009): 15-27.

Bertram, Corrine C. and M. Sue Crowley. "Teaching about Sexual Violence in Higher Education: Moving from Concern to Conscious Resistance." Frontiers: A Journal of Women Studies. 33.1 (2012): 63-82.

Chu, Seo-Young. "Woven: A Refuge for Jae-In Doe: Fugues in the Key of English Major." Entropy. 3 November 2017. entropymag.org/a-refuge-for-jae-in-doe-fugues-in-the-keyof-english-major/. Accessed 20 June 2020.

Denial, Catherine. "A Pedagogy of Kindness.” Hybrid Pedagogy. 15 August 2019. https://hybridpedagogy.org/pedagogy-of-kindness/. 20 June 2020.

Fowler, Susan. "Reflecting on One Very, Very Strange Year at Uber." Susan Fowler. Blog. 19 February 2017. www.susanjfowler.com/blog/2017/2/19/reflecting-on-one-very-strangeyear-at-uber. Accessed 20 June 2020.

Hays, Mary. The Victim of Prejudice. $2^{\text {nd }}$ ed. Ed. Eleanor Ty. Broadview, 1998.

Ingrassia, Catherine. "Familiarity Breeds Contentment: Reviving the Strange When Teaching Eighteenth-Century Women Writers." The Eighteenth-Century Intelligencer. March 2017. 8-15.

Lewinsky, Monica. "Emerging from the 'House of Gaslight' in the Age of \#MeToo." Vanity Fair. 25 February 20 eighteen. https://www.vanityfair.com/news/20 eighteen/02/monicalewinsky-in-the-age-of-metoo. Accessed 20 June 2020.

Manne, Kate. Down Girl: The Logic of Misogyny. Oxford UP, 2018.

Me Too. "History and Inception." https://metoomvmt.org/get-to-know-us/history-inception/. 2018. Accessed 1 September 2020.

Pennebaker, James W. "Writing about Emotional Experiences as a Therapeutic Process." Psychological Science, 8.3 (1997): 162-166.

Radcliffe, Ann. A Sicilian Romance. Ed. Alison Milbank. Oxford UP, 2018.

Rich, Adrienne. "Taking Women Students Seriously." In Gendered Subjects: The Dynamics of Feminist Teaching. Ed. Margo Culley and Catherine Portuges. Routledge, 2012. 21-28.

Rowson, Susanna. Charlotte Temple and Lucy Temple. Ed. Ann Douglas. Penguin, 1991. 
Somander, Tanya. "President Obama Launches the 'It's On Us' Campaign to End Sexual Assault on Campus." The White House. 19 September 2014.

https://obamawhitehouse.archives.gov/blog/2014/09/19/president-obama-launches-its-uscampaign-end-sexual-assault-campus. Accessed 20 June 2020.

Todd, Janet. The Sign of Angellica: Women, Writing and Fiction, 1600-1800. Columbia UP, 1989. 